\title{
Implicações das fake news nas práticas de vacinação: relatos produzidos pela equipe de enfermagem
}

\author{
Implications of fake News for vaccination practices: reports produced by nursing team \\ Implicaciones de las noticias falsas em las prácticas de vacinación: informes producidos por el \\ equipo de enfermeira
}

Recebido: 02/08/2021 | Revisado: 12/08/2021 | Aceito: 17/08/2021 | Publicado: 19/08/2021

Lucas Benício Pinto

ORCID: https://orcid.org/0000-0002-6982-6308 Centro Universitário Vale do Salgado, Brasil E-mail: lucas.benicio3663@gmail.com

João Paulo Xavier Silva

ORCID: https://orcid.org/0000-0003-3082-9373 Centro Universitário Vale do Salgado, Brasil E-mail: jpxavier.enf@gmail.com

Vinícius Rodrigues de Oliveira

ORCID: https://orcid.org/0000-0002-9915-0062 Universidade Federal do Rio Grande do Norte, Brasil E-mail: viniciusrodriguesvro@gmail.com

Maria Luiza Santos Ferreira

ORCID: https://orcid.org/0000-0002-2737-5385 Universidade Regional do Cariri, Brasil

E-mail: marialuizasantos2013@gmail.com

Kerma Márcia de Freitas

ORCID: https://orcid.org/0000-0003-3021-4758

Centro Universitário Vale do Salgado, Brasil

E-mail: kermamarcia@gmail.com

Roberta Peixoto Vieira

ORCID: https://orcid.org/0000-0003-0640-1772

Centro Universitário Vale do Salgado, Brasil

E-mail: roberta.peixotovieira@gmail.com

\begin{abstract}
Resumo
Objetivou-se com o estudo desvelar os relatos e práticas dos profissionais de enfermagem sobre as Fake News e suas implicações nas práticas de vacinação. Concerne a uma pesquisa descritiva-exploratória realizada com oito profissionais da equipe de enfermagem das Estratégias de Saúde da Família de um município cearense, brasileiro respeitando os aspectos éticos e legais pregados pelo Conselho Nacional de Saúde. Foram identificadas duas categorias temáticas empíricas: Concepções sobre Fake News e suas implicações na vacinação; Práxis da enfermagem no contexto das Fake News e Vacinação, que revelaram de que forma os profissionais veem as notícias inverídicas e como essas notícias influenciam em sua atuação, os profissionais precisam deter de conhecimentos para contornar as situações causadas pelos mitos surgidos sobre o processo de vacinação. Evidenciou-se, a necessidade de educação permanente e continuada para os profissionais dessa área com vistas à sua maior qualificação na condução e elaboração de processos educativos em saúde.
\end{abstract}

Palavras-chave: Fake news; Vacinação; Equipe de enfermagem.

\begin{abstract}
The objective of the study was to reveal the reports and practices of nursing professionals about Fake News and its implications for vaccination practices. It concerns a descriptive-exploratory research carried out with eight professionals from the nursing team of the Family Health Strategies of a Brazilian city in Ceará respecting the ethical and legal aspects preached by the National Health Council. Two empirical thematic categories were identified: Conceptions about Fake News and its implications for vaccination; Nursing praxis in the context of Fake News and Vaccination that revealed how professionals see untrue news and how that news influences their performance, professionals need to have knowledge to overcome the situations caused by the myths about the vaccination process. The need for permanent and continuing education for professionals in this area was evidenced, with a view to their greater qualification in the conduct and elaboration of educational health processes.
\end{abstract}

Keywords: Fake news; Vaccination; Nursing team. 


\begin{abstract}
Resumen
El objetivo del estudio fue dar a conocer los informes y prácticas de los profesionales de enfermería sobre Fake News y sus implicaciones para las prácticas de vacunación. Se trata de una investigación descriptiva-exploratoria realizada con ocho profesionales del equipo de enfermería de las Estrategias de Salud de la Familia de una ciudad brasileña en Ceará. respetando los aspectos éticos y legales que predica el Consejo Nacional de Salud. Se identificaron dos categoria temáticas empíricas: Concepciones sobre Fake News y sus implicaciones para la vacunación; La praxis de enfermería en el contexto de las noticias falsas y la vacunación que reveló cómo los profesionales ven las noticias falsas y cómo esas noticias influyen em su desempeño, Los profesionales necesitan tener conocimientos para sortear las situaciones que provocan los mitos sobre el proceso de vacunación. Se evidenció la necesidad de la formación permanente y continua de los profesionales de esta área, con miras a su mayor calificación en la conducción y elaboración de procesos educativos en salud.
\end{abstract}

Palabras clave: Noticias falsas; Vacunación; Equipo de enfermería.

\title{
1. Introdução
}

No Brasil, visando atuar de maneira positiva na prevenção e promoção à saúde, foi criado em 1973 o Programa Nacional de Imunizações (PNI) com o objetivo de reduzir a morbimortalidade por doenças imunopreviníveis. Após o surgimento do Sistema Único de Saúde (SUS), em 1988, o PNI aumentou a cobertura vacinal, tornando-se referência em diversos países (Nóvoa et al., 2020).

Apesar das evidências científicas sobre a eficácia das vacinas no combate e até mesmo erradicação de diversas doenças imunopreveníveis, a acreditação e aceitação das vacinas não é comum a todos, assim o número de vacinados decresce de forma preocupante, a cada ano, movida por diversas razões, dentre as quais pode-se citar o movimento anti-vacinas amparado pela ocorrência das denominadas fake news (Garcia et al., 2020).

O termo fake news corresponde a notícias falsas que, quando disseminadas em canais de comunicação e redes sociais, gera desinformação na população. Essas noticias falsas são ainda mais agravantes ao considerar o cenário pandêmico atual. Na América Latina, por exemplo, estudos apresentam os países que mais disseminaram as fake news sobre a Covid-19 como os que tiveram maior mortalidade a população por essa doença (Nieves-Cuervo et al., 2021; Barcelos et al., 2021).

A população brasileira então é propícia à disseminação de notícias falsas em larga escala, pois está entre os povos mais conectados do mundo. No âmbito da vacinação, essas notícias podem colocar em risco o sucesso já obtido pelo PNI, com o controle das doenças infecciosas e a manutenção da saúde da população (Teixeira, 2018).

O nível de atenção primária à saúde (APS) é cenário propício para a execução das práticas de vacinação, sendo a equipe de enfermagem responsável por esse processo. Esses profissionais são responsáveis pelas ações de manuseio, armazenamento, aplicação, descarte dos resíduos advindos da aplicação das vacinas, além das estratégias de educação em saúde. Em algumas situações precisam unir artefatos e evidências para contrapor as inverdades surgidas nos canais de telecomunicação sobre as ações que os imunizantes provocam (Oliveira et al., 2016; Imamura \& Fagundes, 2021).

Nesse contexto, questiona-se: De que forma as Fake News influenciam na adesão à vacinação? Quais os relatos e práticas dos profissionais de enfermagem acerca dessa temática? Dessa forma, objetivou-se com o presente estudo desvelar os relatos e práticas dos profissionais de enfermagem sobre as Fake News e suas implicações nas práticas de vacinação.

\section{Metodologia}

Concerne a uma pesquisa descritiva-exploratória, desenvolvida de acordo com as recomendações do checklist Consolidated Criteria for Reporting Qualitative Research - COREQ (Tong, Sainsbury \& Craig, 2007). Participaram oito profissionais de enfermagem atuantes na Estratégia Saúde da Família (ESF) de um município do nordeste brasileiro, destes cinco eram enfermeiros e os demais técnicos de enfermagem. 
Para enquadramento dos participantes na pesquisa foram estabelecidos os seguintes critérios de inclusão: ser profissional de enfermagem atuante na ESF, possuir vínculo profissional com o serviço há pelo menos seis meses. Quanto aos critérios de exclusão foram: não atuar no contexto assistencial de vacinação, estar afastado das atividades laborais no período da coleta.

A amostragem constituiu-se de forma não probabilística por acessibilidade. Desse modo, nenhum rigor estatístico foi adotado, sendo selecionados apenas os participantes que foram acessíveis e se dispuseram a participar (Provanov \& Freitas, 2013). Os dados foram coletados de forma remota por meio do aplicativo de mensagens instantâneas @ Whatsapp. A escolha desse aplicativo justifica-se pela facilidade de acesso dos participantes à ferramenta virtual.

Inicialmente, o pesquisador agendou com os participantes um melhor momento para realização da entrevista. No dia e hora marcados a entrevista foi iniciada, à priori com a leitura do Termo de Consentimento Livre e Esclarecido e só tendo prosseguimento com a manifestação de aceite do participante. Em seguida foi realizada a gravação de áudios com perguntas feitas pelo pesquisador e respostas dadas pelo entrevistado, mantendo-se, assim, proximidade com os aspectos de uma entrevista semiestruturada realizada presencialmente.

Para o processo de interpretação de dados foi aplicada a análise categorial temática de conteúdo. Esta por sua vez, operacionaliza-se em três etapas a serem seguidas e que consequentemente estão correlacionadas, a primeira fase que corresponde a pré-análise, a segunda diz respeito sobre a exploração do material e a última expressa o tratamento dos resultados (Minayo, 2014).

No tocante aos aspectos éticos e legais, esta pesquisa foi elaborada conforme os critérios expressos nas resoluções 466/12 e 510/16 do Conselho Nacional de Saúde, que regem as normas, diretrizes e regulamentos a serem seguidos mediante pesquisas que envolvem seres humanos. O projeto foi submetido para avaliação do Comitê de Ética e Pesquisa através da Plataforma Brasil, obtendo parecer favorável sob no 4314172. Salienta-se, ainda, que obedeceu ao disposto no ofício circular 02/2021 do Conselho Nacional de Ética em Pesquisa (CONEP) que trata de pesquisas realizadas em ambiente virtual.

O anonimato dos participantes foi assegurado por meio de atribuições referentes a expressões alfanuméricas (Enf. 1, Enf. 2...) para enfermeiros e (Tec. 1, Tec. 2...) para técnicos de enfermagem durante a apresentação dos resultados.

\section{Resultados e Discussão}

Na caracterização do perfil dos participantes dessa pesquisa, identificaram-se as variáveis de sexo, idade, tempo de atuação na ESF e participação em capacitações relacionadas a temática Fake News e vacinação.

Todas as participantes eram do sexo feminino e possuíam idades que variaram entre 23 e 55 anos. No tocante ao tempo de atuação profissional na ESF, predominou o período de 10 a 20 anos. Nenhuma participante indicou possuir formação ou ter participado de capacitações específicas no contexto abordado na pesquisa.

Desta forma, é notável a demanda de inserção dos profissionais nas qualificações voltadas às Fake News, pois apesar de ser um tema recente para área da saúde, causa impactos negativos. Sendo assim, é necessário que as entidades de saúde promovam eventos que tratem desta temática a fim de qualificar os profissionais que atuam na APS para que estes possam intervir frente a essa problemática (Saraiva \& Faria, 2019).

Referente ao processo analítico viabilizado pela técnica adotada nessa pesquisa, foram identificadas duas categorias temáticas empíricas, a saber: Concepções sobre Fake News e suas implicações na vacinação; Práxis da enfermagem no contexto das Fake News e Vacinação, discutidas a seguir: 


\section{Concepções sobre Fake News e suas implicações na vacinação}

Nessa categoria são retratadas as concepções que as participantes têm sobre as Fake News, os relatos, também apontam para as possíveis implicações das Fake News na vacinação da população. Nesta perspectiva, emergiram núcleos de sentido relacionados a compreensão das Fake News como sendo informações que possuem em parte de sua conjuntura, ou em todo o corpo, dados inverídicos. Essas opiniões são expressas em:

São notícias falsas que muitas vezes interferem, causam na sociedade alguns transtornos para a comunidade e também causam transtornos para a convivência da sociedade de uma maneira geral (Enf. 1)

Já sim, [...] fake news, diria que são informações que são divulgadas, mas que nem sempre possuem uma veracidade concreta mesmo, nem sempre são realmente fidedignas (Enf. 3)

O termo Fake News compreende a produção e disseminação de informações e notícias falsas, que na contemporaneidade possui uma escala cada vez mais larga e crescente. Sua divulgação tem como foco principal manipular a opinião e o conceito das pessoas acerca de determinado fato presente no cotidiano da sociedade, por meio da distorção de fatos de maneira intencional ganhando cada vez mais a atenção da população. Essas notícias direcionam as pessoas a tomarem atitudes errôneas e que ocasionam consequências negativas (Galhardi et al., 2020).

A cultura da desinformação e difusão de notícias falsas no âmbito da saúde não é algo novo, existem inúmeros boatos e inverdades que circulam nas mídias sociais sobre vários assuntos. A área da saúde é um meio bastante favorável para a proliferação, pois devido a falta de confiança e credibilidade em certos momentos para com as autoridades sanitárias e a parcialidade de informações que chegam até a população, fazem com que grande parte das notícias vistas e recebidas, possuam fragmentos de inverdade e calúnias (Henriques, 2018; Sacramento \& Paiva, 2020).

No que diz respeito à identificação de relatos dos usuários sobre as Fake News, predominam falas que apontam para a existência destas em sua realidade, na qual as participantes referem algumas situações no âmbito da vacinação. Os trechos abaixo demonstram essa inferência:

[...] A vacina influenza, a vacina do idoso, eles relatam muito que essa vacina é pra matar o idoso, essa vacina é pra disseminar a população idosa, só mais com essa vacina entendeu (Tec. 1)

Na época que foi introduzida a vacina HPV, então teve muitas conversas que a vacina estava causando problemas neurológicos e eu lembro que na época a gente teve uma rejeição muito grande dessa vacina justamente por conta desses comentários (Enf. 5)

Mesmo que a utilização das vacinas demonstre resultados cada vez mais benéficos, observa-se um crescente aumento no número de pessoas que recusam a vacina para si e seus familiares, isto gera preocupações nas autoridades sanitárias, pois é um fator predisponente para o reaparecimento de patologias já erradicadas no passado e consequente aumento da vulnerabilidade da população a outros fatores de risco (Massarani, Leal \& Waltz, 2020).

Notícias inverídicas possuem capacidade de prejudicar pessoas, grupos, organizações e até mesmo países. A exemplo o que aconteceu no Brasil em 2008, boatos disseminados através do aplicativo de uma mídia social, de que a vacina contra a febre amarela provocava paralisia no fígado, resultaram em um déficit na cobertura vacinal que antes era de aproximadamente 80\% para números próximos à 55\%, em níveis nacionais (Galhardi et al., 2020). 
Adicionalmente, as participantes trouxeram suas percepções relacionadas às possíveis implicações das Fake News na adesão à vacinação, havendo uma concordância de todas as enfermeiras e técnicas de enfermagem que existe uma influência negativa que, inclusive, interfere nas relações entre profissionais e usuários. Visualiza-se essa consideração nos trechos:

Uma notícia falsa dessa desequilibra nosso trabalho, a gente demora a conscientizar a população de novo, atrapalha muito. E agora com esse batalhão de redes sociais, whatsapp, facebook, instagram piorou foi mais, em questão de segundo uma notícia se espalha, complica muito (Enf. 5)

Principalmente porque agora a população, a mais pobre onde a absorção das informaçães que tem através agora de televisão e aparelhos celulares, essas fake news interferem e muito [...] a gente observa muitos movimentos anti vacinas, e por conta disso acaba surgindo doenças né? doenças que a gente já tinha quase erradicado e por conta dessa baixa vacina, baixa adesão acabam ressurgindo (Enf. 1)

As notícias que circulam nas mídias sociais têm influência direta na tomada de decisão das pessoas acerca do uso ou não das vacinas, interferindo no processo de adesão tanto nas campanhas, como na própria rotina de vacinação das UBS. Fatores como o baixo nível cultural, educacional e econômico de pessoas, fazem com que essas pessoas sejam mais propícias a acreditarem e darem continuidade na divulgação desse tipo de notícia (Passos \& Moraes Filho, 2020).

Destarte, essa categoria nos remete à uma compreensão pela qual é possível afirmar que a disseminação de informações errôneas acarreta discussões problemáticas a respeito de assuntos públicos, dentre estes a necessidade das vacinas. Criando um dilema referente a sua necessidade ou não de uso, isto pode proporcionar um atraso ou até mesmo regressão no desenvolvimento da sociedade e na segurança das gerações futuras.

\section{Práxis da enfermagem no contexto das Fake News e Vacinação}

Essa categoria se desdobra sobre a compreensão das participantes acerca da práxis do profissional de enfermagem no contexto das Fake News. Assim, verifica-se a importância da educação continuada como meio de ampliação dos saberes dos profissionais e da educação em saúde para o empoderamento da população contra as notícias falsas, bem como, o papel do ACS, no que tange o combate e orientação, desmistificando e esclarecendo as dúvidas de maneira mais próxima dos usuários, enfatizando o real valor e necessidade do uso dos serviços ofertados, principalmente para a vacinação, que é uma medida de prevenção e manutenção da saúde e bem estar de cada cidadão.

As participantes referem-se à educação em saúde, como um caminho a ser trilhado na luta contra as notícias falsas, ademais relatam a necessidade de que os profissionais de saúde estejam a frente da sensibilização da população. Os recortes das falas a seguir reforçam essas concepções:

Como estratégia [...] educação permanente com os colegas profissionais para que todos estejam cientes que também vão precisar fazer essa propagação e com a população a educação em saúde, que estão diretamente interligados (Enf. 3)

Eu acho que a base realmente é a educação em saúde, seja ela de forma coletiva ou de forma individual [...] no nosso caso que trabalha na saúde da família é trabalhar com os ACS toda uma estratégia de educação continuada para que eles repassem as informações e que também combatam as informações inverídicas (Enf. 6) 
Diante do processo de globalização atrelado ao vasto crescimento e ascensão da internet e das redes sociais, as pessoas têm acesso a grande quantidade de informações e cada vez mais rápido o que pode facilitar a disseminação das Fake News. Em contrapartida, os avanços tecnológicos, presentes nessa era, também têm influência sobre novas tecnologias que são desenvolvidas e disponibilizadas para a população, dentre elas tecnologias da saúde, das quais as vacinas fazem parte. Os imunobiológicos continuamente estão sendo aprimorados e modificados para efetivar um melhor benefícios para as pessoas. Assim, o profissional de saúde deve ter conhecimento sobre o tema e estar atento a atualizações, podendo sanar quaisquer dúvidas e incertezas que a população venha a apresentar (Silva et al., 2017).

Para assegurar que isto ocorra de maneira certa, a educação continuada em saúde é uma das principais e mais importantes peças nesta engrenagem, pois possibilita a constante atualização e aprimoramento dos conhecimentos necessários para o desenvolvimento de boas práticas em saúde (Campos, Sena \& Silva, 2017).

Ademais, a educação em saúde, seja individualizada ou coletiva, tem caráter relevante mediante o contexto abordado, pois visa a construção e formulação de novos conhecimentos que emergem uma análise crítica e reflexiva acerca de diversos assuntos de interesse público. Em uma sociedade onde as Fake News estão ganhando cada vez mais proporções, tais conhecimentos mais aprimorados e específicos demonstram ser uma forte arma para combater tais inverdades, impossibilitando sua disseminação e promovendo a prática da boa informação com respaldo científico verídico (Martins et al., 2019).

Ainda dentro do rol da educação em saúde, as participantes da pesquisa apontam o Agente Comunitário de Saúde (ACS) como um profissional fundamental no processo de conscientização das pessoas da sua comunidade e para tanto também necessitam de capacitações. Os trechos das falas a seguir expõem a percepção das entrevistadas:

O ACS é o profissional que está na ponta, que convive com a população no dia a dia, então a gente tenta estar capacitando ao ACS. Quando tem campanha de vacinas chama os ACS pra fazer uma atualização dizendo para que serve a vacina e como ela deve ser administrada (Enf. 4)

Sempre quando tem campanha (de vacinação), a gente faz a reunião com os ACS para fazer a busca ativa dessas crianças e as mães, a gente acaba fazendo assim, reuniões com os agentes de saúde e orientando as mães sobre a importância das vacinas (Tec. 1)

O ACS tem uma função chave nos processos de educação em saúde, pois possuem um maior vínculo com a população, desse modo, conseguem deter a confiança das pessoas, fazendo com que sua abordagem mediante às Fake News e o esclarecimento de dúvidas acerca do real uso e benefício dos imunobiológicos seja compreendido e aceito pelas pessoas de sua área (Maciel et al., 2020).

Por meio deste contato direto e com uma constância maior, esses profissionais conseguem por meio de uma linguagem mais compreensível por parte dos usuários, promover e disseminar informações em saúde de maneira adequada e eficiente, garantindo assim cada vez mais a eficácia das ações de saúde no âmbito da APS (Araújo, 2017).

\section{Considerações Finais}

A presente pesquisa possibilitou o descortinamento de aspectos inerentes às concepções e práticas de enfermeiras e técnicas de enfermagem no enfrentamento das Fake News e suas implicações no processo de vacinação na APS. Evidenciou-se, a necessidade de educação permanente e continuada para os profissionais dessa área com vistas à sua maior qualificação na condução e elaboração de processos educativos em saúde. 
Como sugestões para futuras pesquisas, define-se a elaboração de pesquisas acerca do ponto de vista do usuário frente a uma informação em saúde recebida ou vista em aplicativo de mensagens, rede social ou até mesmo em diálogos com amigos, vizinhos ou familiares.

\section{Referências}

Araújo, S.J.C. (2017). Capacitação dos agentes comunitários de saúde: relato de experiência. Universidade Federal de Minas Gerais.

Brasil. Ministério da Saúde. Ofício circular nº 2/2021/CONEP/SECNS/MS. http://conselho.saude.gov.br/images/Oficio_Circular_2_24fev2021.pdf.

Barcelos, T. N, Muniz, L. N, Dantas D. M, Cotrim Junior, D.F, Cavalcante, J. R, \& Faerstein, E. (2021). Análise de fake news veiculadas durante a pandemia de COVID-19 no Brasil. Rev Panam Salud Publica., 05:e65.

Campos, K. F. C., Sena, R. R., \& Silva, K. L. (2017). Educação permanente nos serviços de saúde. Esc Anna Nery, 21 (4), e20160317.

Galhardi, C. P., Freire, N. P., Minayo, M. C. S., \& Fagundes, M. C. M. (2020). Fato ou Fake? Uma análise da desinformação frente à pandemia da Covid-19 no Brasil. Ciênc. saúde coletiva, 25 (2), 4201-4210.

Garcia, L. R., Mennezes, L. M. S., Jesus, A. B., Souza, I. M., Côrrea, K. L. D., Marques, L. R., \& Alves, E. A. C. (2020). A importância da vacinação no combate ao sarampo. Brazilian Journal of health Review, 3(6), 16849-16857.

Hennriques C. M. P. A dupla epidemia: febre amarela e desinformação. (2018). Revista Eletrônica de Comunicação Informação e Inovação em Saúde, 12(1), $09-13$.

Imamura, S., \& Fagundes, T. R. (2021). Nursing protagonism in vaccination and evaluation of vaccine coverage against human virus papilloma in municipalities of the 18th regional health of Paraná. Research, Society and Development, 10(7), e7610716410.

Maciel, F. B. M., Santos, H. L. P. C., Carneiro, R. A. S., Souza, E. A., Prado, N. M. B. L., \& Teixeira, C. F. S. (2020). Agente comunitário de saúde: reflexões sobre o processo de trabalho em saúde em tempos de pandemia de Covid-19. Ciênc. saúde coletiva, 25(2), 4185-4195.

Massarari, L., Leal, T., \& Waltz, I. (2020). O debate sobre vacinas em redes sociais: uma análise exploratória dos links com maior engajamento. Cadernos de Saúde Pública, 36(2), e00148319.

Martins, J. R. T., Viegas S. M. F., Oliveira, V. C., \& Rennó, H. M. S. (2019). Vacinação no cotidiano: experiências indicam educação permanente. Esc. Anna Nery, 23(4), e20180365.

Minayo, M. C. de S. (2014). O desafio do conhecimento: pesquisa qualitativa em saúde. (14a ed.). Hucitec.

Nieves-Cuervo, G. M, Manrique-Hernández, E. F., Robledo-Colonia, A. F., \& Grillo, A. E. K. (2021). Infodemia: noticias falsas y tendencias de mortalidad por COVID-19 en seis países de América Latina. Rev Panam Salud Publica, 45:e44.

Nóvoa, T. D., Cordovil, V R., Pantoja, G. M., Ribeiro, M. E. S., Cunha, A. C. S., Benjamim, A. I. M., Silva, C. D. C. C., \& Silva, T. N. (2020). Cobertura vacinal do programa nacional de imunizações (PNI). Brazilian Journal of health Review, 3 (4), 7863-7873.

Oliveira, V. C., Rennó, H. M. S., Santos, Y. R., Rabelo, A. F. G., Gallardo, M. P. S., \& Pinto, I. C. (2016). Educação para o trabalho em sala de vacina: percepção dos profissionais de enfermagem.R. Enferm. Cent. O. Min, 6(3), 2331-2341.

Passos, F. T., \& Moraes Filho, I. M. Movimento antivacina: revisão narrativa da literatura sobre fatores de adesão e não adesão à vacinação. Revista JRG de Estudos Acadêmicos, 3(6), 170-181.

Provanov, C. C., \& Freitas, E. C. de. (2013). Metodologia do trabalho científico: métodos e técnicas da pesquisa e do trabalho acadêmico. (2a ed.). Brasil Biblioteca.

Sacramento, I., \& Paiva, R. (2020). Fake news, WhatsApp e a vacinação contra febre amarela no Brasil. MATRIZes, 14(1), 79-106.

Saraiva, L. J. C., \& Faria, J. F. (2019). A Ciência e a Mídia: a propagação de Fake News e sua relação com o movimento anto-vacina no Brasil. Congresso Brasileiro de Ciências da Comunicação, 42 . https://portalintercom.org.br/anais/nacional2019/resumos/R14-1653-1.pdf

Silva, C. L. (2017). Mídia e ascensão conservadora. Argumentum, 9(2), 172-182.

Teixeira, A. (2020). Fake News contra a vida: desinformação ameaça vacinação de combate à febre amarela. Pontifícia Universidade Católica de São Paulo.

Tong, A., Sainsbury, P., \& Craig, J. (2007). Consolidated criteria for reporting qualitative research (COREQ): a 32-item checklist for interviews and focus groups. Int J Qual Health Care, 19(6), 349-357. 